ISBN 978-93-84468-83-5

International Conference on Issues in Business, Economics, Marketing and Mathematics

(IBEMM-16)

Singapore Dec. 5-6, 2016

\title{
Employer Value Proposition: The Case of MBM TEMPO
}

\author{
Ningky Sasanti Munir ${ }^{1}$ \\ ${ }^{1}$ Senior Lecturer, PPM School of Management, Jakarta, INDONESIA
}

\begin{abstract}
The employer value proposition (EVP) is a set of associations and benefits that will reliably obtained by employees and candidates - if the candidates joined the employer. According to previous studies, the success of an employer or organizations to attract qualified candidates and retain quality employees affected by EVP. Therefore, this study was conducted to identify the EVP as perceived by employees and candidates. This exploratory research was conducted in the news magazine MBM TEMPO, using a qualitative approach. Data was obtained primarily through interviews and questionnaires to management and internal employees as well as employee candidates. Information from internal documents, especially documents related to human resources management system is also used as references. Three important findings are: components of the EVP offered by the management are in line with the perception of employees working under the tenure of 10 years; there are differences of components of the EVP between employees who work under the tenure of 10 years with over 10 years; and there are differences of components of the EVP between employees with employee candidates. In addition to these findings, also discussed initiatives that can be undertaken by MBM TEMPO to communicate its EVP to employee candidates.
\end{abstract}

Keywords: employer value proposition, exploratory, qualitative, human resource management

\section{Introduction}

MBM Tempo is a prominent magazine in Indonesia, also known as a media that rely on news with honest and balanced coverage. In accordance with the development of its business, MBM Tempo continues to increase the number of its human resources. For the last five years the ratio of the number of applicants and the number of candidates who pass the selection are very small, due to the discrepancy between the applicants' qualifications and high quality selection standard of the company.

Candidates who pass the selection process then must attend 1 to 2 years reporter training programs conducted by national well known writers and journalists. Unfortunately, some of the candidates who pass the selection process were not completed all stages of reporter training program due to various reasons. While for those who successfully complete all the stages of reporter training programs decided to resign within five years. They chose to join other companies - not necessarily in media industry - that offer more attractive compensation and benefits.

To address the problems, MBM Tempo felt the need to develop a strategy to recruit and retain the best talents by developingemployer-branding strategy. Barrow and Mosley (2005) state that the development of employer brand can enhance the attractiveness of a company, to recruit potential candidates, and lead to higher level of employee engagement, retention, and brand advocacy.

To be able to attract high quality talents, a company needs a unique employer offer. That is why a company needs to formulate employer value proposition (EPV) before developing its employer branding strategy (Kucherov and Zavyalova, 2012). According to universum, (http://universumglobal.com/business- 
solutions/employer-value-propositi-on-development/) a prominent organization in employer branding strategy, "employer value proposition is a unique set of offerings, associations and values to positively influence the target candidates and employees." The EVP gives current and future employees a reason to work for an employer and reflects the company's competitive advantage.

Based on the above background, this study was conducted with four objectives. The first is to identify the components of EVP perceived by potential employees. The second is to identify the components of EVP perceived by existing employees. The third is to identify the components of EVP set by senior executives of MBM Tempo. The last is to investigate the differences and similarities of perception regarding components of EVP of the three parties: prospective employees, existing employees, and senior executives.

\section{Theoretical Background}

\subsection{Employer Branding}

Brand is one of the highly valuable corporate assets; therefore, brand management is a key activity that should be done by the company. Although companies generally focus their branding efforts to develop products and brands of the company, branding can also be used in the field of human resource management (Backhaus and Tikoo, 2004). The application of the principles of branding in human resources management has been called the "employer branding." Increasingly companies are using the employer brand to attract candidates and ensure that employees are involved in the culture and strategy of the company. The employer brand is defined as a "target, long-term strategy to manage the awareness and perceptions of employees, potential employees, and stakeholders associated with a particular company" (Chhbra and Sharma, 2011). Brand employer puts forth images that show the organization as a good place to work (Chhbra and Sharma, 2011).

According to Backhaus and Tikoo (2004), employer branding is a relatively new approach in attracting and retaining the best talents in an increasingly competitive work environment. Employer brand has the potential to be a valuable concept for managers and academics. Employer branding is a term used to describe how organizations market their offers to prospective employees as well as employees, communicate and maintain their loyalty, and to promote both within and outside the company, a clear view of the things that makes the company different and desirable as a workplace (Wilska, 2014).

Being a desired workplace is one component of the talent management strategy. Wilska (2014) states that employees who feel the action is consistently performed by the company will be more comfortable to stay in the company. The commitment of the employees in the organization will increase and the quality and quantity of candidates applying for various positions in the organization will increase. According Aruman (2014), an organization that has a strong employer brand can create a competitive advantage by helping employees internalize the values of the company and assist in retaining employees. Based on the theories above, it can be seen that the employer branding strategy can provide benefits in the form of competitive advantage for companies that have it, and it's one of the benefits is the ability of firms to retain our employees. These benefits are expected to address issues faced by MBM Tempo.

\subsection{Employer Value Proposition}

Barrow and Mosley (2005) state that the company must have a quality brand that will be sold to customers and employees. The need for customers and employees can be different; therefore, a special design is required for each party, i.e. customers and employees. The need for the customer (customer brand proposition) is designed to get the interest of customers towards the products or services sold by the company. As with the need for the customer, the need for employees (employer brand proposition) is designed to get the interest and attraction of potential employees, and also to motivate, retain the loyalty and commitment of the employees working at the company. 
According to Schumann and Sartain (2010), employer branding is how the company articulates its employervalue proposition (EVP) so that prospective employees are aware of the benefits of working at the company. Things that need to be noticed by potential employees, among others, what the company does, how secure the enterprise, how good wages, how the prospects for the future, who will be the boss, and like any employee employed at the company. EVP is the reason for job candidates interested to join the company and the reasons employees to survive in the company.

Ambler and Barrow (1996) divide EVP into three components: functional, economical, and psychological. The three components of EPV can be obtained from job and identified from the employer company. Kucherov and Zaylalova (2012) added the fourth components: organization.

In 2006 and 2009, a talent-management consulting firm, Sibson Consulting (sibson.com), conducted a study on the factors that influence employee engagement(Insler, 2008). Through Sibson's Reward of Work (ROW) Study, a model of employer value proposition was developed. The model consists of five components of EPV representing the factors that most influential to employee engagement. Some components are financial some are non-financial. The five components are also a blend of functional, economical, psychological, and organizational aspects. The five components are (Insler, 2008):

1. Affiliation - "The feeling of belonging I have to my institution" : organization commitment, work environment, citizenship, and trust;

2. Benefits - "Indirect compensation including health, retirement, time off, and tuition reimbursement": health, retirement, recognition, perquisites;

3. Career - "The long-term opportunities I have for development and advancement": advancement, personal growth, training, employment security

4. Compensation - "The money I receive for my work and performance"; base salary, incentives, cash recognition, premium pay, pay process;

5. Work Content - "The satisfaction that comes from the work I do": variety, challenge, autonomy, meaningfulness, and feedback.

\section{Methodology}

This research was conducted in MBM TEMPO, a strategic unit of PT. Tempo Inti Media Tbk. (public company). This research was specifically conducted on the working unit that became a core part of the company's business: the production unit. The number of employees at the production unit is approximately $60 \%$ of the total number of employees working full time in the company. They are consists of writer, reporter and editor. This qualitative research with explorative approach utilizes information obtained in three ways: the study of internal company documents, interviews with internal and external sources, as well as a survey on internal and external respondents. Content analysis is used to process information and gain meanings from internal documents analysis and interviews. Categorization refers to the five components of Sibson's EVP model.

Study of internal documents conducted on two groups of documents. The first is the group's internal documents concerning human resources management, which provide information on the number of employees, profile, performance, training and development, recruitment and selection, including the information regarding the level of turnover during the past five years. The second is the Annual Report of Tempo Inti Media Tbk. (public company) year 2014 and 2015, which includes, among others, strategic plan of MBM Tempo 2015-2019. The documents also contained a description of the vision, mission, and values of the company. Protocol of document study refers to the five components of Sibson's EVP model.

The survey was conducted using a simple questionnaire to obtain information on the importance of the components of EPV according to informants and the satisfaction level of fulfillment in MBM Tempo. Factors in the questionnaire referred to the five components of Sibson's EVP model. The questionnaire is divided into two parts. The first part asks about the importance ranking of five components of EPV and respondent satisfaction. The second part asks how important and how satisfied respondents, based on Likert scale. A total of 50 questionnaires were distributed to all employees, including the executive employees. 34 questionnaires returned, 
14 of the employees with tenure of less than 10 years and 20 employees with tenure of over 10 years. All questionnaire return can be processed.

The same questionnaire distributed to 21 employees who are following the candidate selection process and 50 students who are writing theses, all of which are students of Communication Studies Journalism specificity at a public university and a private college. As in the internal employee MBM Tempo, a questionnaire aimed at obtaining information on the importance of the elements of EPV. For the level of satisfaction, a questionnaire aimed at obtaining information of employees and student perceptions of the candidates regarding how satisfying elements of EPV can be met by working at MBM Tempo.

Interviews were conducted with three groups of informants. Selection of informants was purposively. The first was with two representatives of the Board of Directors and two executive managers at MBM TEMPO. Interviews were conducted also with each of the four informants who represent groups of writer, reporter, and editor. Of the 16 internal resource persons, seven have tenure less than five years, while the rest have tenure of over 10 years. Interviews with representatives of the Board of Directors and executive managers performed twice, before the questionnaires were distributed and after the questionnaire is processed. In addition to internal sources, interviews were also conducted with employee candidates: five candidates who are following the selection process and five students from the School of Communication and Journalism at two universities in Jakarta. Structured interview protocol refers to the five components of Sibson's EVP model.

\section{Results and Discussion}

Table 1 shows the ranking of the importance of EPV's components as perceived by the employee, the employee candidates, and students. While Table 2 shows the ranking of satisfaction with the implementation of the EPV's components as perceived by employees, employee candidates, and students. Discussions on the results are given in five sub-chapters below.

TABLE I: Importance of EPV's Components

\begin{tabular}{clllll}
\hline \hline RANK & & \multicolumn{3}{c}{ IMPORTANCE } & \\
\hline & Management & Employee $>10$ & Employee $<10$ & Candidates & Students \\
\hline 1 & Work Con & Benefits & Work Con & Work Con & Work Con \\
\hline 2 & Career & Work Con & Career & Career & Career \\
\hline 3 & Benefits & Compensation & Compensation & Affiliation & Affiliation \\
\hline 4 & Affiliation & Affiliation & Benefits & Benefits & Compensation \\
\hline 5 & Compensation & Career & Affiliation & Compensation & Benefits \\
\hline \hline
\end{tabular}

TABLE II: Satisfaction of EPV's Components

\begin{tabular}{clllll}
\hline \hline RANK & & \multicolumn{3}{c}{ SATISFACTION } & \\
\hline & Management & Employee $>10$ & Employee $<10$ & Candidates & Students \\
\hline 1 & Work Con & Work Con & Work Con & Work Con & Work Con \\
\hline 2 & Affiliation & Affiliation & Career & Affiliation & Affiliation \\
\hline 3 & Career & Career & Affiliation & Career & Career \\
\hline 4 & Benefits & Benefits & Compensation & Benefits & Benefits \\
\hline 5 & Compensation & Compensation & Benefits & Compensation & Compensation \\
\hline \hline
\end{tabular}

\subsection{Work Content}

From Table 1 it is known that for all informants, both internal and external, the work content component is considered very important. Interviews with internal informants indicate that existing employees feel their work is important because it inspiring, evocative, or pursuing truth. Informants said that their job is not easy because often limited by the deadline; it is not easy to obtain accurate and reliable information, and almost always involving a lot of data and information: 
"... yeah right ... .time is very limited, the sources are so many and they are difficult to approach .....yes we have to find ways ... .we have to ... this is not just important for us here, but it is important for the reader, this is a very serious job"

"... when we have all the information ... .mountain of it ... ..lots of information ... mountain of information ... and need to analyze all of it in a short time. We have to work fast, smart, and accurately, you know! "

Informants also add that sometimes there are obstacles and threats because there are parties who are not happy with the articles. Many kinds of threats, from law sued, also bombs. Although difficult and challenging, all the informants said they are happy because his/her work is useful and appreciated:

"... we was investigating an issue ... our reporters received threats, even physical ... yes it's true ... ..we published the article ... it's kind of funny..because we become the headline of other media...at that time our office was occupied by a group of hostile people...."

"In 2010, yes, yes ... a Molotov cocktails was hurled at our office .."

"Our writings led to many prestigious awards ... .."

"... I'm sure with what we are doing is helpful ... from articles followed by investigation by the authorities ... and many prestigious awards.."

Not only internal employees, employee candidates and students expressed that the work content is the most sought after in the work and is something that should be obtained by people who have a profession as a journalist. Informant also felt the profession of journalists is an interesting job because it is not boring:

"If you do not like the challenge, do be a journalist"

"I want to be a journalist because I like the challenge"

"Tempo already had a reputation. The investigation is killing! Become Tempo's journalist is definitely challenging "

"My work is my hobby, yes. It's an interesting job, it is not boring. Topics are varied, going around here and there, met a variety of people as well."

Employee candidates and students feel confident that working at MBM Tempo will provide satisfying work content. For the internal employees, MBM Tempo viewed as a place to work, which is very satisfactory in terms of work content.

\subsection{Careers and Affiliation}

Career in EPV include aspects of advancement, personal growth, training, and employment security. The management of MBM Tempo agrees with all other informants that career is an important component of EPV. The management said that the company allocated a substantial budget to develop employees. Through the development program journalists increase their competence and also increase the capability to handle complex assignment. In the end it increases the quality of the work and also employee satisfaction. In addition to formal development programs, management also provides personal and team development through special assignments, also coaching with senior journalists.

With the outstanding reputation of MBM Tempo, the company got a lot of offers of scholarships to study abroad, in attractive programs, in leading schools overseas. With so many scholarship offers, for short term and long-term study, management has decided to control who may join what program and when. After returning from long-term studies, most employees remain as employees in MBM Tempo, but some choose to quit and join another organization:

"Yes we know that, ... employees returning from long-term study program abroad usually quit to work in international organizations ... mostly the international non-profit organization .."

Opportunities for self-development are remarkable. It makes external informants such as employee candidates and students interested in working at MBM Tempo. The reputation of MBM Tempo at national and international levels has convinced candidates and students that they will be able to develop themselves as a high quality journalist through collaboration with leading journalists, complex assignments, and study abroad:

"I believe that by working in Tempo we have the opportunity to work with top journalists, for example [names of Indonesia famous journalists]... .." 
"... they have lots of break-through innovations .."

"... I heard that by only join the reporter training programs we already couldimprove our competence significantly..."

TEMPO MBM reputation that supported by people who are well-known experts in the field did not make the internal informants, including management; clearly felt that affiliation is an important component:

"..well, we are famous ... but..how shall I say ... it's the result of everyone, .... I think everyone realized that his job is important ... yes it is important.."

"... .we must trust one another's work, it's normal here...."

"It's fun to work here because of the people, because of their culture, there was no superiors and subordinates ... all this time...it's never change..."

The external informants have a different perception on affiliation. They felt that being part of a well-known organization such as TEMPO MBM is important and interesting:

"I think the working environmentis nice. Imagine, lots of discussions and debates with experience people who won many awards in their field..."

"... Their writing style is a legend!"

The management, internal and external informants agreed that MBM Tempo could fulfill affiliation componentsatisfactory. Existing employees with tenure either under or over 10 years old said that during this time they are very aware of being part of a democratic organization that is famous nationally and internationally. The internal informants also admits their coworkers are funny, full of creative ideas, and smart.

\subsection{Benefits and Compensation}

Survey and interview about the benefits and compensation components showed an interesting thing. Both internal and external informant felt that the benefits and compensation components are lacking in both MBM Tempo. In terms of importance, the external informants and existing employees with tenure under 10 years feel that the benefits and compensation is important, but less important than other components of EPV. One very good reason is the realization that the work as a journalist is a job that does not bring in much money:

"I think it is difficult to get a high salary by working in Tempo,.....they the idealists .."

"... If you want to be rich... well,....do not be a journalist"

"Yes, my God, I was confused when people want to be rich and chose to be a journalist.."

"... Later maybe we can get a lot of benefits, ... someday...."

For the management, offering competitive benefits and compensation in the industry is felt not easy. This is because large business groups dominate the media industry in Indonesia. The conglomerates are funded their media businesses through business activities in other strategic business units in the business group.

\section{Practical Implications and Further Studies}

The study of EPV components in MBM Tempo indicates that three components: work content, career and affiliation, are important EPV components for existing employees and external candidates. All of the informants also stated that MBM Tempo could fulfill these components satisfactorily. These three EPV componentsneed to be communicated to the candidate employees through employer branding strategy. The internship activities that have been implemented by MBM Tempo are an effective way to make employees candidates familiar with the company. It has build very positive image of the organization.

However the management needs to be aware of the benefits component, which considered very important by existing employees with tenure over 10 years. They perceive this component is not well fulfilled. To respond to this effectively, a deeper strategic analysis of the MBM Tempo as a business company is needed. Also considering MBM Tempo who has relatively different characteristics than other media in Indonesia, further study needed to identify most important EPV components in Indonesia media industry. 


\section{References}

[1] Ambler, T. and S. Barrow. The Employer Brand. Journal for Brand Management vol. 4, no. 3, pp: 185-206, 1996. https://doi.org/10.1057/bm.1996.42

[2] Aruman, E.SebutSajaDengan Employer Branding. MIX.August 2014.

[3] Backhaus, K. and S. Tikoo. Conceptualizing and Researching Employer Branding. Career Development Internationalvol. 9, no. 4, pp: 501-517, 2004.

https://doi.org/10.1108/13620430410550754

[4] Barrow, S. andR. Mosley.The Employer Brand Bringing the Best of Brand Management to People at Work.Chichester, U.K.: John Wiley \& Sons Ltd. 2005.

[5] Chhabra, Neeti L. and S. Sharma. Employer Branding: Strategy for improving employer attractiveness. International Journal of Organizational Analysis, vol. 22, no. 1, pp: 48-60, 2011 https://doi.org/10.1108/IJOA-09-2011-0513

[6] Insler, D. Maximizing the EVP for your MPVs: What Motivates the Sales Force May Surprise You. Perspective vol. 16, Iss. 1, 2008.

[7] Kucherov, D. and E. Zavyalova. HRD Practices and Talent Management in The Companies with The Employer Brand. European Journal of Training and Development vol. 36, no. 1, pp: 86-104, 2012.

https://doi.org/10.1108/03090591211192647

[8] Schumann, M. and L. Sartain. Brand for Talent 8 LangkahJituMenciptakan BrandUntukMemikat SDM yang TepatpadaSaat Yang Tepat. Jakarta: Penerbit PPM, 2010.

[9] Wilska, E. Employer Branding as An Effective Tool in Acquiring Talents. Journal of Positive Management vol. 5, no. 3, pp: 46-54, 2012.

https://doi.org/10.12775/JPM.2014.019 